\title{
Phyto-response effects of moringa oleifera leaves (moringa oleifera) ethanol extract on osteoblast and mandibular bone osteoclasts (rattus norvegicus) (experimental study using histopathology fluorescent light)
}

\author{
Chairunas, ${ }^{1 *}$ Basri A. Gani, ${ }^{2}$ Munifah Abdat, ${ }^{3}$ Salwa D. Kariza ${ }^{2}$
}

\section{Abstract}

Objective: To determine the phyto-response effect of the Kelor leaves ethanol extract (Moringa oleifera) in osteoblasts and osteoclasts cells of rat mandibular bones (Rattus norvegicus) in the atmosphere of fluorescent light histopathologically.

Material and Methods: Manufacture of Kelor leaf ethanol extract by maceration method and ethanol 96\%. The 10-tailed mice are divided into 1 mouse-tails that are only exposed to light, 3-tailed mice positive groups given the drug vitamin D, 3-tails of negative group rats given aquades, and 3-tails of treatment given the leaf ethanol extract. The treatment of rats was carried out on the 0 day, 7th Day, 14th and 21st days, then dieutanasia using ether anesthesia and carried out the cutting of the mandibular bone using bone, fixation, decalcification to the calculation of cells osteoblasts and osteoclasts with a microscope (Olympus BX-51) 400X magnification.

Results: There was a significant difference between the positive control group, the negatives and the treatment group that applied the Kelor leaf ethanol extract to the rat mandibular bone and exposed to light for 24 hours. The treatment group applied the Kelor leaf ethanol extract has the highest number of osteoblasts cells on day 28.

Conclusion: The Kelor leaf ethanol extract is effective in stimulating the osteoblasts cells of the bones that have been exposed to light in the long term. The Kelor leaf ethanol extract can balance the bone growth cycle significantly over vitamin D.
${ }^{1}$ Department of Oral Maxillofacial Surgery, Faculty of Dentistry, Universitas Syiah Kuala, Banda Aceh, Indonesia

${ }^{2}$ Department of Oral Biology, Faculty of Dentistry, Universitas Syiah Kuala, Banda Aceh, Indonesia ${ }^{3}$ Department of Dental Public Health, Faculty of Dentistry, Universitas Syiah Kuala, Banda Aceh, Indonesia

*Correspondence to: Chairunas, Department of Oral Maxillofacial Surgery, Faculty of Dentistry, Universitas Syiah Kuala, Banda Aceh, Indonesia

chairunas.omfs@unsyiah.ac.id

Received: 6 June 2020

Revised: 10 July 2020

Accepted: 26 November 2020

Available Online: 1 December 2020

Keywords: Light bulbs, Mandibular bones, Moringa oleifera, Osteoblasts cells, Osteoclast cell Cite this Article: Chairunas, Gani BA, Abdat M, Kariza SD. 2020. Phyto-response effects of moringa oleifera leaves (moringa oleifera) ethanol extract on osteoblast and mandibular bone osteoclasts (rattus norvegicus) (experimental study using histopathology fluorescent light). Journal of Dentomaxillofacial Science 5(3): 191-195. D01: 10.15562/jdmfs.v5i3.1065

\section{Introduction}

The human motion system is composed by bones, muscles, and joints. ${ }^{1}$ The arrangement of various bones is called a skeleton that has complex functions including structurally, protective, motion tools, and as a reserve for calcium and phosphate. ${ }^{2}$ One of the unique body skeleton that is facial bones, plays a role in mastication and speech are the jawbones. ${ }^{3,4}$

The jaw bone is divided into two namely the maxilla and the mandible, as the age continues to experience growth to increase the accumulation of bone mass in puberty and decreases after puberty. ${ }^{3,5}$ in relation to bone growth, nutrients play an important role in bone cells, including proteins, carbohydrates, calcium, vitamin $\mathrm{D}$, and fat. ${ }^{5}$ The results of Macdonell's ${ }^{5}$ research mention that the effects of complex nutrients will encourage bone formation and control age-related bone loss.

The maxilla and mandibular bones contain a connective tissue, dynamic and have bone cells and extracellular matrices as the constituent of bone structure. ${ }^{6,7}$ The bone cells consist of; osteogenic cells, osteoblasts cells, bone-lining cells, osteoocyte cells, and osteoclasts cells. ${ }^{8,9}$ Osteoblasts and osteoclasts cells play an important role in bone formation and resorption processes. ${ }^{6,7}$

Bone formation and resorption are the basis of the bone cycle of growth, modeling and remodeling. ${ }^{10}$ In addition to nutrition, there are several factors that can affect the bone cycle such as endogenous and exogenous factors. ${ }^{11}$ Endogenous factors include genetic, hormonal, metabolic whereas exogenous factors include nutrients, physical and psychological aspects. ${ }^{11}$ One of the physical aspects that can affect bone growth is light. ${ }^{12,13}$

The light is divided into two of the natural and man-made. ${ }^{12}$ natural light that is from the sun can stimulate vitamin D in the body thereby increasing the absorption of calcium in the intestines and transferring calcium across the cell membrane, so as to strengthen the bones..$^{13}$ While light from man-made like lights, computers, video games, and 24-hour lighting in hospitals. Researching mice 
exposed to light bulbs constantly causing muscles to become weaker and experiencing early-stage osteoporosis signs. ${ }^{14}$

Generally to prevent signs of early-stage osteoporosis, most people use synthetic drugs that can stimulate bone repair and development among others, vitamin D, Kalsitriol, Calcitonin and bisphosphonate..$^{15}$ but each group of drugs has a bad side effect for the patient. 15 due to many adverse effects of synthetic drugs that are bad for the health of patients, now some research on herbal medicines from plant Moringa oleifera known as Kelor leaves have many benefits one of them osteoprotection. ${ }^{16-18}$ Some other researchers have even claimed that Moringa's plant oleifera can inhibit inflammatory mediators by reducing the formation of osteoclasts and can stimulate the activity of osteoblas. ${ }^{18}$

Therefore, researchers are interested to know the effect of phyorespon from the administration of kelor-leaf ethanol extract through the absorption mechanism against the development of osteoblasts and osteoclasts of rat mandibular bones (rattus norvegicus) in a fluorescent light atmosphere.

\section{Material and Methods}

The manufacture of Kelor leaf extract (moringa oleifera) was conducted in the Chemistry laboratory of the Faculty of Mathematics and Natural Sciences Universitas Syiah Kuala. The leaves of kelor (moringa Oleifera) as much as $1 \mathrm{~kg}$ obtained from Ajun, Aceh Besar District and Unsyiah Dormitory, Darusalam, Banda ACEH with the criteria of a young leaf, green in color.

The parts of the Kelor plant taken are the leaves are then dried and cooled down for 2-4 days later grinded to a fine powder with the help of a blender. The powder is then stored in an airtight container and placed in a dry, dark and cool container. The method of extraction used is the maceration method with ethanol solvent $96 \%$. Separation of residue and filtrate carried out every $1 \times 24$ hours for 3 days interspersed with the same solvent replacement. Filtrate is collected and is centered at a temperature of $50^{\circ} \mathrm{C}$ using a vacuum rotary evaporator so that a condensed extract is obtained.

The trial animals used in this study were 10 rat-tailed (rattus norvegicus) at 2-3 months old with a bodyweight of 200-300 G. The number of rats sampled Wistar (rattus norvegicus) as much as 10 rat tails. The wistar mouse (rattus norvegicus) as much as 1 tail is used for light exposure prior to treatment, and the remainder is divided into 3 groups with 3 mice each group. The group consists of a negative control group that the akuades apply, a positive control group applied topically vitamin $\mathrm{D}$ and a treatment group applied with kelor leaf extracts (moringa oleifera).

Before application of Akuades, vitamin D and Kelor leaf extract, the whole mouse is displayed by fluorescent lamp light in each enclosure for 24 hours for 7 days. On the 7 th day, a single rat has used ether anaesthesia to see the damage to the mandible bone. Fluorescent lamps are still displayed in mice until the 28th day.

The Wistar mouse treatment starts at D0 displayed light on each enclosure. In the treatment group applied the leaf extract of the Kelor (Moringa oleifera) topically using cotton bud on a rat mandibular. In a positive control group administered vitamin $\mathrm{D}$ supplement as well as in the negative control group administered akuades. The D0 starts with a 24-hour light exposure. D7 One-tailed rat Rattus Norvegicus performed euthanasia using ether anaesthesia. D8-D29: The treatment group applied the Kelor Leaf ethanol extract (Moringa oleifera) in rat mucosa using a cotton bud on the mandible mucosa of rats 2 times a day, a positive control group applied to vitamin D supplements topically on the mandibular mucosa of rats using cotton bud 2 times a D14 and D21 three-tailed rats Rattus norvegicus each of the negative control groups and the treatment group performed euthanasia using ether anaesthesia.

After the treatment ends, the dietetic rats use ether anaesthesia. Further cutting of mandibular bone is used in bone. The results of bone surgery of mandibular rats were inserted in a $10 \%$ Neutral Buffer Formalin (fixation) solution for 24 hours. Then decalcification using EDTA 14\%, done dehydration, clearing, embedding paraffin, as well as cutting using longitudinal directional microtom with a thickness of 5 micro for Dyeing procedure Hematoxylin Eosin (HE). The staining procedure is done using $\mathrm{HE}$ to figure out the histological description of osteoblasts and osteoclasts cells. The calculation of osteoblasts and osteoclasts cells is carried out using a microscope (Olympus BX-51) 400X magnification.

Data analysis is done by SPSS software. The research Data was analyzed with a test of One Way Analysis of Variance (ANOVA) with $\mathrm{p}<0.05$ to see the influence of Kelor leaf extracts (Moringa oleifera) on the development of osteoblasts and osteoclasts in the Fdibular rat Wistar (Rattus norvegicus).

\section{Results}

Obtained by Kelor leaf extract (Moringa oleifera) with the Maceration method using the $96 \%$ ethanol solvent, obtained a pure extract of $250 \mathrm{gr}$ figure 1. 


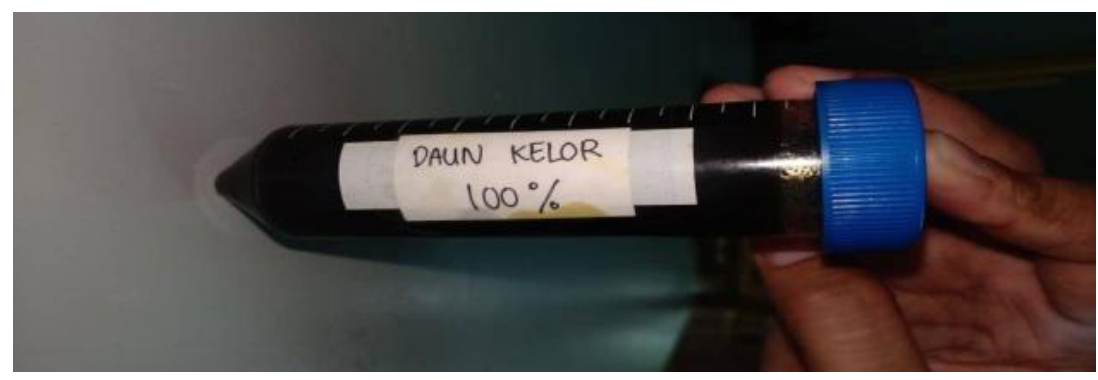

Figure 1 Ethanol Extract from Moringa

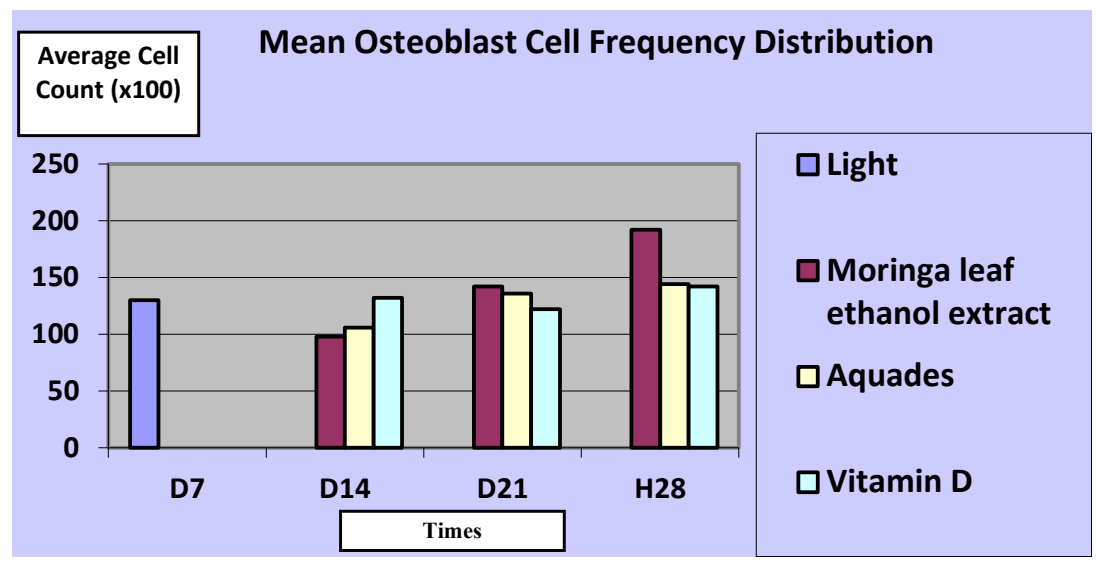

Figure 2 Figure of the Average Graph of Osteoblast Cell Frequency Distribution on Day 7, 14, 21, and Day 28



Figure 3 Figure of Average Graph of Osteoclast Cell Frequency Distribution on Day 7, 14, 21, and Day 28

The results of observations under the microscope against the mandibular bones indicate a variation of the histopathology change figure 2. The image of the mandible of Rattus norvegicus on the 7th day after exposure to fluorocene lamps for 24 hours without the administration of the Kelor leaf ethanol extract, the histopatological structure of cell calculations with a five-point view indicates the average number of osteooblasts cells less than osteoclasts. On the 14th day showed a histopatological structure with an average number of osteoblasts cells in more positive control groups and in the treatment group showed a slight amount. As for the histopathology structure averages the number of osteocweld cells in more treatment groups and in the positive control group indicate a slight amount. On the 21st day shows the histopatological structure with the average number of osteoblasts cells in the treatment group of more kelor-leaf ethanol extract and in the positive control group indicates a slight amount. As for the histopathological structure with an average number of osteoclas in the positive control group more and in the treatment group showed a slight amount. On the 28th day showed the histopatological structure of osteoblasts cells in more treatment groups and in the positive control group showed a slight amount. Figure 2.

While the histopathology structure of osteocweld cells in more treatment groups and in the positive control group indicates a slight amount. Figure 3.

Based on the test results of significant data normality with the value $\mathrm{p}>0.05$ indicates normal distributed data. The test result of Osteocweld cell data homogenization shows the significance result of the value $\mathrm{P}=0.073$ and the Osteocweld cell data shows the result of significance $\mathrm{P}=0.462(\mathrm{P}>0.05)$ which can be concluded that the data is homogeneous. Statistically with ANOVA's test obtained the effect of extracting kelor ethanol extract of the osteooblasts cells and osteoclas of the rat mandible of Rattus norvegicus in a hystopathology fluorescent light.

\section{Discussion}

Osteoblasts and liquid osteoclasts of cells in the bones that contribute to repentance in the bone cycle. ${ }^{6,7}$ osteoblasts are involved in the formation of generally rounded bones and lines on the bone surface whereas osteoclasts are many giant crux cells responsible for bone resorption. Based on the observation result histopathology of rat mandibular bone Rattus norvegicus, the average number in $\mathrm{D} 7$ osteoblasts is fewer than osteoclasts. These results due to long-term light exposure that caused the disruption of analog estrogens acting on repentance in osteoblasts cell metabolism in the bones, consequently the activity of osteoclasts increased. ${ }^{19,20}$ Of these outcomes support research from the current journal of Biology examining mice displayed 24-hour lamp light for 24 weeks which causes changes in bone microstructure characteristic of the early stages of osteoporosis. ${ }^{14}$ In addition, Feskanich and Quevedo et.al. examined the human night workers who were always exposed to lamps 
that had increased risk of fractures and decreased bone mineral density. ${ }^{20,21}$

While the average number of osteoblasts in a group of treatment with the administration of Kelor leaf ethanol extract initiated D8 experienced a significant increase in D21 and D28, while osteoclas cells experienced a decline of D14 but increased on D21 and D28. The results of the Products that in the long-term light exposure condition (24 hours) during 28 days supported the previous study in which it would undergo the cell changes of osteoblasts and osteoclasts in rat mandibular bone Rattus norvegicus, in addition, it is influenced by the content of the Kelor leaf ethanol extract, which is reported in previous studies that the flavonoids compounds have a positive effect on the bones with a stimulating effect on the activity of osteoblasts through estrogen-mediatedaction. ${ }^{22,23}$ Whereas for the average results of the Osteoclas the cell illustrates that on the D14 down allows its sole from the extract of the Kelor later on D21 and D28 increased allegedly that the existence of phase renovation stage early for $0-2$ weeks i.e. the Aktiviasi and resorption phases in which the role of increased osteoclas activity in charge of the rupture of broken bones balanced by osteoblasts cells is also increased in this treatment group. ${ }^{23}$

The average number of osteoblasts and osteoclasts cells in the negative control group is equally increased. The result of the increase of osteoblasts cells slightly compared to osteoclas cells that increase larger it illustrates no balance in the bone cycle. While in the positive control group the average number of osteoblasts cells increased at D 14 and D28 Products increase after application of vitamin D is evidenced from previous research where vitamin D quality in the prevention of early osteoporosis, but in D21 decreased suspected vitamin D can not control the change in the cycle of bone cells accompanied by increased osteoclasts due to light exposure.

\section{Conclusion}

There was a significant difference in the osteooblasts cells and osteoclasts of the rat mandible of Rattus norvegicus, which was displayed for 24 hours with the treatment of the Kelor leaf ethanol extract. Kelor leaf ethanol extract can stimulate osteoblasts cells on the mandible bone of the Rattus norvegicus which is exposed to light for 24 hours. Kelor leaf Ethanol extract can balance the bone growth cycle significantly over vitamin D.

\section{Acknowledgment}

The author would like to thank the Chemistry Laboratory of the Faculty of Mathematics and Natural Sciences (FMIPA) Unsyiah for permission and for facilitating this research process.

\section{Conflict of Interest}

The authors report no conflict of interest.

\section{References}

1. Hidayat A, Mujahiduddien A. Learning the shape of the human joint uses the concept of augmented reality. J Siliwangi 2017;3: 204-208. (In Indonesia)

2. Doherty AH, Ghalambor CK, Donahue SW. Evolutionary physiology of bone : bone metabolism in changing environments. Physiol 2015;30: 17-29.

3. Edelson LR, Loret C, Re BJD Le. Anatomical, functional, physiological and behavioural aspects of the development of mastication in early childhood. Br J Nutr 2014;111: 403-414.

4. Dias PEMD, Miranda GE, Beaini TL, et al. Practical application of anatomy of the oral cavity in forensic facial reconstruction. J Pone 2016;11: 1-16.

5. Macdonell R, Hamrick MW, Isales CM. Protein / amino-acid modulation of bone cell function. Bonekey Rep 2016;5: 1-7.

6. Florencio-silva R, Rodrigues G, Sasso-cerri E, et al. Biology of bone tissue: structure, function, and factors that influence bone cells. Biomed Res Int 2015;2015: 1-17.

7. Lin X, Patil S, Gao YG, Qian A. The Bone Extracellular Matrix in Bone Formation and Regeneration. Front Pharmacol 2020;11: 1-15.

8. Morris CA, Cabral D, Cheng H, et al. Patterns of bone mineral density testing: Current guidelines, testing rates, and interventions. J Gen Intern Med 2004;19: 783-790.

9. Boskey AL. Mineralization of bones and teeth. Elements 2007;3: 385-391.

10. Walsh JS. Normal bone physiology, remodelling and its hormonal regulation. Surg 2014;33: 1-6.

11. Lungu A, Punga A, Mangaloiu D, et al. Factors affecting growth and bone development in minors. Case report. Eur J Public Health 2018;25: 456-457.

12. Guo R, Du Y, Zhang S, et al. The effects of ultraviolet supplementation to the artificial lighting on rats' bone metabolism, bone mineral density, and skin. J Photochem Photobiol B Biol 2018;188: 12-18.

13. Sinar A, Surakarta B, Kunci K. The Effectiveness of Sunlight Ultraviolet Exposure on Bone Mass Density and Cholesterol Levels in the Elderly. Profesi 2016;14: 1-4. (In Indonesia)

14. Lucassen EA, Coomans CP, van-Putten $M$, et al. Environmental 24-hr cycles are essential for health. Curr Biol 2016;26: 1843-1853.

15. Syarif RD, Kusumaningsih T, Arundina I. Changes in osteoblast and osteoclast cell count after moringa oleifera leaf extract administration during orthodontic tooth movement. J Dentomaxillofac Sci 2020;5: 98-102.

16. Fitriana WD, Ersam T, Shimizu K, et al. Antioxidant activity of moringa oleifera extracts. Indones J Chem 2016;16: 297-301.

17. Soekobagiono, Salim S, Hidayati HE, et al. Effects of moringa oleifera leaf extract combined with DFBBX on type-1 collagen expressed by osteoblasts in the tooth extraction sockets of Cavia cobaya. Dent J 2018;51: 86-90. 
18. Rostiny, Djulaeha E, Hendrijantini N, et al. The effect of combined moringa oleifera and demineralized freezedried bovine bone xenograft on the amount of osteoblast and osteoclast in the healing of tooth extraction socket of cavia cobaya. Dent J 2016;37: 38-43.

19. Cardinali DP, Ladizesky MG, Boggio V, et al. Melatonin effects on bone: experimental facts and clinical perspectives. J Pineal Res 2003;34: 81-87.

20. Feskanich D, Hankinson SE, Schernhammer ES. Nightshift work and fracture risk: the nurses' health study. Osteoporos Int 2009;20: 537-542.

21. Quevedo I, Zuniga AM. Low bone mineral density in rotating-shift workers. J Clin Densitom 2010;13: 467-469.

22. Farbod K, Nejadnik MR, Jansen JA, Leeuwenburgh SCG. Interactions Between Inorganic and Organic Phases in Bone Tissue as a Source of Inspiration for Design of Novel Nanocomposites. Tissue Eng - Part B Rev 2014;20: 173-188.
23. Kresnoadi U, Rahmania PN, Caesar HU, et al. The role of the combination of moringa oleifera leaf extract and demineralized freeze - dried bovine bone xenograft (xenograft) as tooth extraction socket preservation materials on osteocalcin and transforming growth factor - beta 1 expressions in alveo. J Indian Prosthodont Soc 2019;19: 120-125.

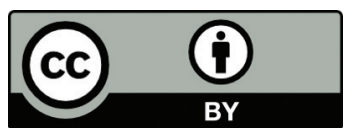

This work is licensed under a Creative Commons Attribution 